Studia nad Autorytaryzmem i Totalitaryzmem 43, nr 1

Wrocław 2021

https://doi.org/10.19195/2300-7249.43.1.11

MACIEJ PICHLAK

ORCID: 0000-0001-5113-9537

Uniwersytet Wrocławski

maciej.pichlak@uwr.edu.pl

\title{
Sytuacja autorytarna i rządy prawa. Socjologiczno-prawne wyjaśnienia kryzysu konstytucyjnego*
}

Słowa kluczowe: kryzys konstytucyjny, autorytaryzm, sytuacja autorytarna, autorytaryzm społeczny, autorytaryzm polityczny, konstytucjonalizm, konstytucjonalizm społeczny, państwo prawa.

\section{AUTHORITARIAN SITUATION AND RULE OF LAW. SOCIO-LEGAL EXPLANATIONS OF THE POLISH CONSTITUTIONAL CRISIS}

\begin{abstract}
The paper surveys the existing explanations of the current Polish constitutional crisis. For that sake the paper adopts a socio-legal perspective and introduces the concept of authoritarian situation, interpreted as a complex of social conditions which enable and/or facilitate the authoritarian form of government. As the examined studies prove, such an authoritarian situation has made a constitutional crisis in Poland possible. The paper discusses the explanations which concentrate on various factors conditioning the crisis, such as: class antagonism, the conflict of ideologies, the general legal culture of Polish society, professional legal culture, binding legal rules, and the condition of legal institutions (of law-making, law-applying, and constitutional politics). This discussion allows a conclusion that the causes of the constitutional crisis are multiple and much deeper than the current political conflict.
\end{abstract}

Keywords: constitutional crisis, authoritarianism, authoritarian situation, social authoritarianism, political authoritarianism, constitutionalism, societal constitutionalism, rule of law.

* Artykuł powstał w ramach realizacji projektu badawczego „Modele prawnej regulacji ryzyka w świetle teorii refleksyjności" (nr projektu 2016/23/B/HS5/00873), finansowanego przez Narodowe Centrum Nauki. 


\section{Wprowadzenie}

Niniejszy artykuł ma na celu przegląd i omówienie formułowanych w literaturze przedmiotu wyjaśnień obecnego, trwającego od 2015 roku, kryzysu konstytucyjnego (dalej: kryzysu). Sam fakt jego wystąpienia jest dość powszechnie przyjmowany ${ }^{1}$, jakkolwiek w jego interpretacjach i ocenie występują znaczne różnice. W opracowaniu tym nie interesują mnie jednak opinie na temat procesów składających się na kryzys ani jego szczegółowy przebieg, a jedynie próba uchwycenia warunków społecznych, które umożliwiły powstanie takiego stanu rzeczy. Tekst ma więc charakter socjologiczno-prawny i bazuje na analizie dostępnej literatury, dążąc do ustalenia, jakie czynniki złożyły się na tak zwaną sytuację autorytarną, która z kolei stworzyła warunki do odejścia od wcześniejszego paradygmatu konstytucyjnego ustroju państwa prawa.

$\mathrm{W}$ artykule, z racji jego socjologiczno-prawnego charakteru, przyjmuję podstawowe założenie metodologiczne nauk społecznych o racjonalności społecznych aktorów. Zgodnie z nim należy uznać, że społeczne przyzwolenie na działania władzy wobec instytucji prawnych jest postawą racjonalną, wynikającą z zaistniałych warunków społecznych. Zamiast więc oceniać lub próbować reformować tego rodzaju postawy, staram się zdiagnozować okoliczności, które do nich doprowadziły.

Główna teza niniejszego tekstu brzmi, że u podstaw obecnego kryzysu państwa prawa stoją procesy i zjawiska społeczne, które można opisać za pomocą pojęcia sytuacji autorytarnej. Przez sytuację autorytarną rozumiem zespół warunków społecznych, które umożliwiają lub ułatwiają rozwój autorytarnej formy rządów. Innymi słowy, czynniki te stoją u podstaw rozwoju autorytaryzmu państwowego. Do powstania sytuacji autorytarnej może dochodzić w różnych podsystemach społecznych: w gospodarce, prawie, polityce, administracji publicznej, systemie medialnym itp. Niniejszy tekst koncentruje się na warunkach powstałych w podsystemie prawnym w pierwszych dekadach XXI wieku. Pozostawiam więc poza zakresem rozważań sytuację w innych podsystemach, takich jak systemy politycz$n y^{2}$ czy gospodarczy ${ }^{3}$. Staną się one przedmiotem zainteresowania jedynie tam, gdzie wprost oddziałują także na prawo.

Pojęcie sytuacji autorytarnej jest powiązane ze zbliżoną kategorią autorytaryzmu społecznego, proponowaną w ramach nurtu badawczego określanego mia-

${ }^{1}$ Zob. na przykład P. Radziewicz, Kryzys konstytucyjny i paradygmatyczna zmiana konstytucji, „Państwo i Prawo” 2020, nr 10, s. 3-24; W. Sadurski, Polski kryzys konstytucyjny, przeł. A.W. Wójcik, Łódź 2020.

2 Badania z tego obszaru wpisują się najczęściej w światowy nurt rozważań nad kryzysem demokracji liberalnej i wzrostem znaczenia populizmów. Zob. T. Sawczuk, Nowy liberalizm. Jak zrozumieć i wykorzystać kryzys III RP, Warszawa 2018; W. Sadurski, op. cit.; The End of the Liberal Mind. Poland's New Politics, red. K. Wigura, J. Kuisz, Warszawa 2020.

${ }^{3}$ M. Gdula, Nowy autorytaryzm, Warszawa 2018. 
nem społecznego konstytucjonalizmu ${ }^{4}$. Podejście to, jako skoncentrowane na tym, w jaki sposób konstytucyjne normy i instytucje funkcjonują w rzeczywistych stosunkach społecznych, wydaje się szczególnie użyteczne przy porządkowaniu badań nad społecznymi uwarunkowaniami kryzysu konstytucyjnej zasady państwa prawa.

Posłużenie się pojęciem sytuacji autorytarnej nie oznacza oczywiście uznania, że polski system polityczny ma aktualnie charakter autorytarny. Wśród badaczy panuje w zasadzie powszechna zgoda, że klasyczne kategorie autorytaryzmu nie przystają do polskich realiów. Jednak, po pierwsze, pojawiły się w polskim systemie pewne elementy typowe dla tendencji autorytarnych, przede wszystkim w postaci konsolidacji władzy oraz osłabiania jej instytucjonalnych ograniczeń; po drugie, wystąpienie w danym państwie sytuacji autorytarnej może, ale nie musi, prowadzić do wykształcenia się tego typu rządów. Oznacza ona jedynie, że pojawiły się społeczne uwarunkowania sprzyjające politycznej autorytaryzacji. Jak wykazują omawiane w dalszej części badania, taka właśnie sytuacja zaistniała w polskim porządku prawnym.

Dostępne wyjaśnienia kryzysu można porządkować według różnych kryteriów. W tym artykule przyjmuję kryterium perspektywy teoretycznej, która dostarcza ram interpretacyjnych dla formułowanych twierdzeń wyjaśniających. Podążam tutaj za propozycją Łukasza Fyderka, który w badaniach nad autorytaryzmem wyodrębnił perspektywy klasową, kulturową oraz instytucjonalną ${ }^{5}, \mathrm{z}$ tym zastrzeżeniem, że podejście klasowe uznaję za wariant szerszej kategorii wyjaśnień odwołujących się do antagonizmów społecznych.

\section{Interpretacje antagonistyczne}

Podejścia należące do tej grupy możemy podzielić na koncentrujące się na antagonizmie klasowym albo na konflikcie ideologicznym. W kontekście rozważań nad polskim kryzysem pierwsza z tych perspektyw może ujawniać się (przynajmniej potencjalnie) na dwa sposoby — po pierwsze, poprzez wskazywanie na klasowy charakter samego prawa, którego treść miałaby sprzyjać określonym klasom czy grupom społecznym, co powinno skutkować obniżoną legitymizacją prawa w szerokich warstwach społeczeństwa; po drugie, jako uzasadnienie dla twierdzeń, zgodnie z którymi środowiska prawnicze (w szczególności tak zwane elity) miałyby orientować się przede wszystkim na obronę własnych interesów klasowych i korporacyjnych. Trudno jednak o poważne analizy kryzysu z którejkol-

${ }^{4}$ D. Sciulli, Theory of Societal Constitutionalism. Foundations of a Non-Marxist Critical Theory, Cambridge 1991. Zob. też K. Muszyński, P. Skuczyński, Rozwój i kryzys konstytucji spotecznej. Przypadek samorząów zawodowych, Warszawa 2020, s. 17 n.

5 Ł. Fyderek, Autorytarny system polityczny. Przeglad ujęć teoretycznych, „Politeja” 2011, nr 3 (17), s. 111-128. 
wiek z tych perspektyw. Jeśli chodzi o pierwszą z nich, klasową analizę prawa, to jest ona $w$ bardzo niewielkim stopniu obecna w rodzimym prawoznawstwie. Jednocześnie prowadzone w Polsce badania w paradygmacie klasowym w bardzo ograniczonym zakresie uwzględniają problematykę prawną ${ }^{6}$.

Z kolei zarzuty o prawniczej obronie środowiskowych interesów były formułowane w ostatnich latach stosunkowo często ${ }^{7}$, obarczone są one jednak istotnymi ograniczeniami. Po pierwsze, sprowadzają się najczęściej do wskazywania na korporacyjną lojalność, ewentualnie także rzekome dziedzictwo postkomunistyczne, mniejszą wagę przywiązując do szerszych kwestii klasowych. Po drugie, prezentowane tezy nie wychodzą zwykle poza poziom publicystyczny. Brakuje poważniejszych opracowań o charakterze naukowym, które w sposób poprawny metodologicznie uwiarygadniałyby tego rodzaju retoryczne oskarżenia.

Znacznie szerzej reprezentowane są w prawoznawstwie interpretacje kryzysu z perspektywy konfliktu ideologii, w szczególności zaś populizmu jako reakcji na ideologię dominującą. Taki status przypisywany jest demokracji liberalnej, która zmonopolizowała nie tylko rodzimy dyskurs konstytucyjny i doktrynę państwa prawa $^{8}$. W czasach swojej dominacji ideologia ta przedstawiana była jako neutralna i bezalternatywna; monopolizacja dyskursu konstytucyjnego doprowadziła do kontrreakcji i wysunięcia alternatywnych propozycji ideologicznych. Największe znaczenie zyskały obecnie stanowiska populistyczne, budujące swoją siłę między innymi na niechęci wobec „elit”. Przyczyniło się to do kryzysu na co najmniej dwa sposoby: po pierwsze, już sama demistyfikacja rzekomo neutralnej doktryny państwa prawa jako uwikłanej ideologicznie prowadzi do osłabienia jej legitymizacji ${ }^{9}$. Po drugie, ponieważ to właśnie elity kształtowały i najmocniej wspierają

${ }^{6}$ Na przykład M. Cebula, Analiza klasowa na rozdrożu? W stronę kulturowej koncepcji klas P. Bourdieu, „Studia Socjologiczne” 2017 nr 3 (226), s. 33-69; Klasy w Polsce. Teorie, dyskusje, badania, konteksty, red. M. Gdula, M. Sutowski, Warszawa 2017. Spośród publikacji bezpośrednio poświęconych kryzysowi zob. M. Gdula, Nowy...

${ }^{7}$ Na przykład W. Biedroń, M. Nawacki, Czy „kasta” sędziowska pozostanie bezkarna?, http://wpolsce.pl/magazyn/14393-czy-kasta-sedziowska-pozostanie-bezkarna (dostęp: 30.06.2021); M. Marosz, Resortowe togi, Warszawa 2017; L. Morawski, A Critical Response, https://verfas sungsblog.de/a-critical-response/ (dostęp 20.04.2018). W łagodniejszej wersji stwierdzano, że elity prawnicze pozostają wyalienowane i niezainteresowane problemami niższych klas, zob. A. Czarnota, Constitutional correction as a third democratic revolutionary moment in Central Eastern Europe, „Hague J Rule Law” 11, 2019, nr 2-3, s. 397-406.

8 Zob. na przykład seria artykułów A. Sulikowskiego, zwł. idem, Apolityczność w prawoznawstwie. Kryzys idei a zjawisko populizmu, „Archiwum Filozofii Prawa i Filozofii Społecznej” 2018, nr 3, s. 74-87. Zob. też M. Stambulski, Populizm a konstytucjonalizm, [w:] Nowy konstytucjonalizm. Polityczność, tożsamość, sfera publiczna, red. A. Czarnota et al., Warszawa 2021, s. 5380. Tekst ten w interesujący sposób włącza problematykę antagonizmów ekonomicznych. Adam Czarnota podziela diagnozę o kryzysie ideologii liberalnej, nie zgadzając się jednak na opis sytuacji w Polsce po 2015 roku w kategoriach populizmu: idem, op. cit.

${ }^{9}$ H. Dębska, T. Warczok, Sakralizacja i profanacja. Trybunat Konstytucyjny jako struktura mityczna, „Państwo i Prawo” 2018, nr 5, s. 63-74. 
liberalny porządek konstytucyjny, populistyczni liderzy stosunkowo łatwo mogą przedstawiać go jako zasługujący na odrzucenie. Jak widać, o ile interpretacje klasowe polegają na połączeniu perspektywy prawnej z ekonomiczną, o tyle analizy odwołujące się do kategorii populizmu mają charakter prawno-polityczny.

\section{Interpretacje kulturowe}

Perspektywa kulturowa przy wyjaśnianiu sytuacji autorytarnej odwołuje się do (specyficznych dla państwa lub regionu) czynników obecnych w kulturze polityczno-prawnej całego społeczeństwa bądź w sprofesjonalizowanej kulturze prawniczej. W pierwszym wariancie zwraca się przede wszystkim uwagę na takie cechy polskiej (czy też środkowoeuropejskiej) kultury prawnej jak brak głębszego zakorzenienia instytucji i zasad państwa prawa w świadomości społecznej. Przyjęta w konstytucji doktryna rządów prawa nie została więc odpowiednio społecznie zinternalizowana i zinstytucjonalizowana ${ }^{10}$. W tym duchu Grażyna Skąpska pisze między innymi o ,pustce aksjologicznej”, z jaką na poziomie konstytucyjnym mamy do czynienia po 1989 roku w państwach regionu tworzących „labilną przestrzeń" między Wschodem a Zachodem ${ }^{11}$. Autorka stwierdziła również, że etniczno-narodowy model wspólnoty politycznej, który ma dominować w polskiej świadomości społecznej, odbiega od liberalnych wzorców, na których próbowano opierać konstrukcję konstytucyjnego państwa prawa ${ }^{12}$.

Innym istotnym czynnikiem kulturowym jest bardzo niski poziom zaufania do konstytucyjnych instytucji państwa prawa, w szczególności do wymiaru sprawiedliwości. Dość powiedzieć, że w ocenie działalności sądów opinie negatywne od dekad trwale przeważają nad pozytywnymi, a dwie trzecie Polaków nie uważa sędziów za niezawisłych. Problem ten był wielokrotnie na przestrzeni ostatnich dekad diagnozowany $\mathrm{w}$ badaniach ${ }^{13}$ i opisywany w literaturze ${ }^{14}$.

10 M. Krygier, Przez 25 lat demokraci młotkowali, że konstytucja jest ważna, zamiast pomyśleć, co zrobić, żebyśmy ja pokochali, http://wyborcza.pl/magazyn/7,124059,24939520,przez-25-lat-demokraci-mlotkowali-ze-konstytucja-jest-wazna.html (dostęp: 21.01.2020).

11 G. Skąpska, Od, ,legalnej rewolucji” do kontrrewolucji. Kryzys konstytucjonalizmu liberalno-demokratycznego w Polsce, „Przegląd Prawa i Administracji” 110, 2017, s. 65-81. Zob. również B. Bugarič, Kryzys demokracji konstytucyjnej w postkomunistycznej Europie. „Ziemia niczyja” między demokracja a autorytaryzmem, [w:] Nowy konstytucjonalizm..., s. 123-174.

12 G. Skąpska, Znieważający konstytucjonalizm i konstytucjonalizm znieważony. Refleksja socjologiczna na temat kryzysu liberalno-demokratycznego konstytucjonalizmu w Europie pokomunistycznej, „Filozofia Publiczna i Edukacja Demokratyczna” 2018, nr 7 (1), s. 276-301.

13 Zob. na przykład CBOS, Spoleczne oceny wymiaru sprawiedliwości, Warszawa 2017; CBOS, Polacy o zmianach $w$ sadownictwie, Warszawa 2020.

${ }^{14}$ Zob. na przykład Sądy w opinii społeczeństwa polskiego, red. M. Borucka-Arctowa, K. Pałecki, Kraków 2003; K. Daniel, Kryzys społecznego zaufania do sądów, „Studia Socjologiczne” 2007, nr 2, s. 61-82. Na te źródła kryzysu zwraca uwagę również Jacek Sokołowski, pisząc, że „sądownictwo przez obywateli postrzegane jest jako nieprzyjazny labirynt" — idem, Dlaczego Polacy 
Drugi wariant interpretacji kulturowych zwraca uwagę na sprofesjonalizowaną kulturę prawniczą, czyli samoświadomość przedstawicieli środowisk prawniczych. Spośród wielu wchodzących tu w grę czynników, takich jak stan nauk prawnych, edukacji prawniczej itp., zwróćmy uwagę na dwa najczęściej podnoszone w literaturze. Są to nadmierny formalizm w wykładni i stosowaniu prawa oraz stan społecznego „wyalienowania” prawników. Wydaje się zresztą, że zjawiska te były wspierane do pewnego stopnia świadomie jako strategie legitymizacji prawa ${ }^{15}$.

Jak można wywnioskować z dostępnej literatury, formalistyczny styl interpretacji i stosowania prawa przyczynił się do kryzysu co najmniej na dwa sposoby. Po pierwsze, miałby on być odpowiedzialny za znaczny stopień alienacji prawa i aktów jego stosowania, które w niedostatecznym stopniu uwzględniają zmieniające się kontekst i oczekiwania społeczne ${ }^{16}$. Po drugie, formalizm pozbawił środowiska sędziowskie skutecznych narzędzi przeciwstawienia się wątpliwym prawnie działaniom władzy, które sprokurowały kryzys ${ }^{17}$.

Drugi z czynników wiąże się z kulturowym wzorcem roli prawnika, w tym zwłaszcza sędziego, jako „sfinksa"18. możliwie zdepersonifikowanego, zdystansowanego wobec sprawy oraz stron postępowania, kryjącego się za proceduralnym rytuałem i powagą urzędu. W konsekwencji, choć sędziom nie brakuje profesjonalizmu, to już wymiana perspektyw między nimi a „cywilnymi” uczestnikami postępowania jest bardzo utrudniona; ci pierwsi zdają się nie rozumieć emocji i oczekiwań „cywilów”, jak i sami czują się niezrozumiani. W polskich sądach zdaje się dochodzić do smutnego paradoksu: dążąc do budowy własnego autorytetu, sędziowie wybierają strategię opierania się na powadze reprezentowanego przez nich państwa; ponieważ jednak ono samo nie cieszy się w oczach znacznej części obywateli autorytetem, sądy stają się forum dla wyrażania frustracji wobec wszelkich jego instytucji ${ }^{19}$.

nie bronia sędziów? Szukając wyjścia z błędnego koła (cz. 1), https://klubjagiellonski.pl/2020/01/21/ dlaczego-polacy-nie-bronia-sedziow-szukajac-wyjscia-z-blednego-kola/ (dostęp 30.06.2021).

15 Zob. H. Dębska, T. Warczok, op. cit.; A. Sulikowski, op. cit.

16 A. Czarnota, The Constitutional Tribunal, https://verfassungsblog.de/the-constitutionaltribunal/ (dostęp: 20.04.2018); A. Uzelac, Survival of the Third Legal Tradition?, „Supreme Court Law Review” 2010, nr 49, s. 377-396.

17 M. Matczak, The Clash of Powers in Poland's Rule of Law Crisis. Tools of Attack and SelfDefense, „Hague J Rule Law” 12, 2020, nr 3, s. 421-450.

18 S. Burdziej, Sprawiedliwość i prawomocność. O społecznej legitymizacji władzy sadowniczej, Toruń 2017. Zob. też M. Kurkchiyan, Comparing Legal Cultures: Three Models of Court for Small Civil Cases, „Journal of Comparative Law” 5, 2010, nr 2, s. 169-193.

19 Por. ibidem. 


\section{Interpretacje instytucjonalne}

Również w ramach perspektywy instytucjonalnej można wyodrębnić dwa warianty związane $\mathrm{z}$ odmiennym sposobem rozumienia samego pojęcia instytucji: tym przyjętym w prawoznawstwie oraz tym funkcjonującym w pozostałych naukach społecznych, zwłaszcza socjologii. Pierwszy z nich koncentruje się na instytucjach prawnych jako zespołach norm prawnych, uznając, że pewne przyjęte w polskim porządku prawnym rozwiązania normatywne umożliwiły lub ułatwiły działania prowadzące do kryzysu. Jest to więc zwrócenie uwagi na słabość samego prawa — szczególnie regulacji konstytucyjnej — które nie zawiera skutecznych mechanizmów ograniczania i równoważenia władz w celu obrony przed kryzysem. Taki sposób wyjaśniania wydarzeń ostatnich lat prezentowany jest przez niektórych rodzimych i zagranicznych badaczy prawa konstytucyjnego ${ }^{20}$.

Wyjaśnienia prawnicze mają tę niewątpliwą zaletę, że wskazują na względnie latwe do zmiany — bo będące w gestii prawodawcy — uwarunkowania, których modyfikacja mogłaby w przyszłości zapobiegać lub przeciwdziałać kryzysowi. Ich wadą jest jednak ujmowanie jego przyczyn w dość płytki sposób i z negatywnej perspektywy: tłumaczą one, dlaczego kryzys nie został powstrzymany. Nie są natomiast w stanie wyjaśnić, jakie czynniki społeczne doprowadziły do sytuacji autorytarnej, umożliwiając kryzys w sensie pozytywnym.

Tych słabości pozbawiony jest socjologiczny wariant wyjaśnienia instytucjonalnego. Jednocześnie z perspektywą prawniczą łączy go ta zaleta, że wskazuje na poddające się zmianie uwarunkowania kryzysu. Oczywiście instytucjonalne wzorce działania względnie trudniej zmienić niż uregulowania prawne, nie jest to jednak niewykonalne. Wyjaśnienia te koncentrują się na działaniu instytucji społecznych związanych z systemem prawnym ${ }^{21}$ — instytucji tworzenia, stosowania i egzekwowania prawa - które przyczyniło się do powstania sytuacji autorytarnej.

Jak pokazały na przykład badania Jacka Kurczewskiego ${ }^{22}$ lub Jana Winczorka i Karola Muszyńskiego ${ }^{23}$, instytucje wymiaru sprawiedliwości nie stanowią

20 W. Brzozowski, O potrzebie reformy konstytucyjnej, „Państwo i Prawo” 2017, nr 12, s. 3-22; T. Ginsburg, A.Z. Huq, How to Save a Constitutional Democracy, Chicago-London 2018; M. Kruk, Czy praktyka ustrojowa wskazuje na konieczność zmian w Konstytucji?, „Państwo i Prawo" 2018 , nr 12, s. 38-55.

${ }^{21} \mathrm{~W}$ teorii socjologicznej nie istnieje jeden sposób definiowania instytucji społecznych; na potrzeby niniejszego tekstu można odwołać się do wzorcowej definicji Jonathana H. Turnera, zgodnie z którą instytucja to tyle, co „zespół pozycji, ról, norm, wartości osadzonych w pewnych rodzajach struktur społecznych i organizujących względnie trwałe wzorce ludzkiego zachowania" idem, The Institutional Order, New York 1997, s. 6. Zob. S. Miller, Social Institutions, [w:] The Stanford Encyclopedia of Philosophy, red. E.N. Zalta, https://plato.stanford.edu/archives/sum2019/ entries/social-institutions/ (dostęp: 30.06.2021).

22 Zob. na przykład J. Kurczewski, Prawem i Lewem. Kultura prawna społeczeństwa polskiego po komunizmie, „Studia Socjologiczne” 2007, nr 2.

23 J. Winczorek, K. Muszyński, Dostęp do prawa wśród matych i średnich przedsiębiorców. Raport z badania empirycznego, Warszawa 2019. 
dla obywateli skutecznego narzędzia służącego do rozwiązywania problemów czy rozstrzygania sporów. Jak zauważyli autorzy drugiego z opracowań, polscy przedsiębiorcy - mimo sporej świadomości prawnej — rzadko korzystają z prawa jako efektywnego narzędzia rozwiązywania problemów czy rozstrzygania sporów; wejście na ścieżkę prawną jest bowiem często postrzegane jako kosztowne, uciążliwe i nieprzewidywalne. Instytucje prawne odbierane są więc jako mało użyteczne i niesprawne, co skutkuje nikłym społecznym zaangażowaniem w ich obronę w momencie kryzysu. Jak na kanwie przeprowadzonych badań stwierdzili autorzy: „Długofalowe gwarancje rządów prawa mogą wynikać tylko z poprawiania dostępności instytucji prawnych i usług prawniczych. Muszą one stanowić dla zwykłych obywateli użyteczne narzędzia rozwiązywania problemów w kluczowych obszarach życia"24.

Na nieco inny problem zwracają uwagę Paweł Skuczyński z Karolem Muszyńskim w przywoływanej już pracy, w której na przykładzie samorządów zawodowych przedstawili obszerną, instytucjonalną analizę procesu legislacyjnego. Jak wprost zauważyli, tendencje do konsolidacji władzy i marginalizowania znaczenia partnerów społecznych - wpisujące się w zjawisko społecznego autorytaryzmu - rozwijały się na długo przed 2015 rokiem. W ten sposób w obszarze instytucji stanowienia prawa wytworzona została sytuacja autorytarna, umożliwiająca rozwój kryzysu ${ }^{25}$.

Trzecią grupą instytucji, które przykuwają uwagę badaczy, są instytucje polityki konstytucyjnej, umożliwiające obywatelom czynny udział w kształtowaniu podstawowych zasad ustrojowych ${ }^{26}$. Chodzi tu więc o propozycje takich reform instytucjonalnych, które stworzyłyby warunki do aktywizacji i mobilizacji obywateli, przeciwdziałając alienacji konstytucyjnej (a co za tym idzie, sytuacji autorytarnej). Propozycje takie łączą w sobie prawnicze i socjologiczne spojrzenie na instytucje warunkujące kryzys.

\section{Wnioski}

Trwający od 2015 roku kryzys konstytucyjny budzi silne społeczne emocje i skrajnie różne oceny. Niezależnie jednak od stosunku do składających się nań

24 J. Winczorek, K. Muszyński, Skąd kryzys państwa prawa? Ludzie nie czuli, że formalne instytucje prawne działaja. Trzeba to naprawić, https://oko.press/skad-kryzys-panstwa-prawa-ludzie-nie-czuli-ze-formalne-instytucje-prawne-dzialaja-ale-wiadomo-jak-to-naprawic/ (dostęp 30.06.2021). W podobny sposób argumentuje J. Sokołowski, op. cit.

${ }^{25}$ K. Muszyński, P. Skuczyński, op. cit.

26 P. Blokker, New Democracies in Crisis? A comparative constitutional study of the Czech Republic, Hungary, Poland, Romania and Slovakia, London-New York 2015; K. Kaleta, Bezpośrednia partycypacja obywateli w polityce konstytucyjnej (wyzwania i ograniczenia), „Państwo i Prawo" 2020, nr 5, s. 3-24. 
zjawisk, przedstawiona analiza dostępnych wyjaśnień kryzysu musi prowadzić do kilku wniosków.

Po pierwsze, przyczyny kryzysu leżą znacznie głębiej niż tylko w aktualnym konflikcie politycznym. Warunki społeczno-prawne, które go umożliwiły, kształtowały się bowiem na długo przed jego wystąpieniem. Składają się one na to, co określiłem jako sytuację autorytarną. Nie oznacza to zwolnienia z ewentualnej odpowiedzialności za podejmowane w trakcie kryzysu niezgodne z prawem działania. Wynika z tego jednak, że skuteczne wyjście z obecnej sytuacji nie może być dokonane jedynie za sprawą politycznej woli i modyfikacji treści obowiązujących tekstów prawnych, ale wymaga zmiany warunków społecznych, które kryzys umożliwiły.

Po drugie, wspomniane czynniki mają charakter złożony i wieloaspektowy; choć omówione zostały jedynie te, które odnoszą się do samego podsystemu prawnego, i tak uwzględniają one kwestie kulturowe, instytucjonalne, ideologiczne, a być może także (co pozostaje jedynie hipotezą) klasowo-ekonomiczne. Oznacza to, że odpowiedź na kryzys powinna mieć równie wieloaspektowy charakter.

Jednocześnie, po trzecie, wydaje się, że większość spośród najistotniejszych czynników przyczyniających się do kryzysu można sprowadzić do tezy o - po części celowej, po części niezamierzonej - alienacji czy też separacji prawa. Zgodnie $\mathrm{z}$ nią kulturowe i instytucjonalne uwarunkowania polskiego porządku prawnego czynią go niezdolnym do udzielenia efektywnej odpowiedzi na istotne społeczne potrzeby i oczekiwania. Reakcja na kryzys musi uwzględniać i tę trudność, odnajdując w wymiarze ideologicznym, kulturowym, instytucjonalnym itp. sposoby skutecznego powiązania prawa z jego społecznym otoczeniem.

\section{Bibliografia}

Biedroń W., Nawacki M., Czy „kasta” sędziowska pozostanie bezkarna?, 8.06.2021, http://wpolsce. $\mathrm{pl} /$ magazyn/14393-czy-kasta-sedziowska-pozostanie-bezkarna.

Blokker P., New Democracies in Crisis? A comparative constitutional study of the Czech Republic, Hungary, Poland, Romania and Slovakia, London-New York 2014.

Borucka-Arctowa M., Pałecki K. (red.), Sąy w opinii społeczeństwa polskiego, Kraków 2003.

Brzozowski W., O potrzebie reformy konstytucyjnej, „Państwo i Prawo” 2017, nr 12.

Bugarič B., Kryzys demokracji konstytucyjnej w postkomunistycznej Europie. „Ziemia niczyja” między demokracja a autorytaryzmem, [w:] Nowy konstytucjonalizm. Polityczność, tożsamość, sfera publiczna, red. A. Czarnota, M. Paździora, M. Stambulski, Warszawa 2021.

Burdziej S., Sprawiedliwość i prawomocność. O społecznej legitymizacji władzy sądowniczej, Toruń 2017.

Cebula M., Analiza klasowa na rozdrożu? W stronę kulturowej koncepcji klas P. Bourdieu, „Studia Socjologiczne" 2017, nr 3 (226).

Czarnota A., The Constitutional Tribunal, 3.07.2017, https://verfassungsblog.de/the-constitutional-tribunal/.

Czarnota A., Constitutional Correction as a Third Democratic Revolutionary Moment in Central Eastern Europe, „Hague J Rule Law” 11, 2019, nr 2-3. 
Daniel K., Kryzys społecznego zaufania do sądów, „Studia Socjologiczne” 2007, nr 2.

Dębska H., Warczok T., Sakralizacja i profanacja. Trybunat Konstytucyjny jako struktura mitycz$n a$, „Państwo i Prawo” 2018, nr 5.

Fyderek Ł., Autorytarny system polityczny. Przegląd ujęć teoretycznych, „Politeja” 2011, nr 3 (17).

Gdula M., Nowy autorytaryzm, Warszawa 2018.

Gdula M., Sutowski M. (red.), Klasy w Polsce. Teorie, dyskusje, badania, konteksty, Warszawa 2017.

Ginsburg T., Huq A.Z., How to Save a Constitutional Democracy, Chicago-London 2018.

Kaleta K., Bezpośrednia partycypacja obywateli w polityce konstytucyjnej. (Wyzwania i ograniczenia), „Państwo i Prawo” 2020, nr 5.

Kruk M., Czy praktyka ustrojowa wskazuje na konieczność zmian w Konstytucji?, „Państwo i Prawo" 2018, nr 12.

Krygier M., Przez 25 lat demokraci młotkowali, że konstytucjajest ważna, zamiast pomyśleć, co zrobić, żebyśmy ja pokochali, 29.06.2019, http://wyborcza.pl/magazyn/7,124059,24939520,przez-25-lat-demokraci-mlotkowali-ze-konstytucja-jest-wazna.html.

Kurczewski J., Prawem i Lewem. Kultura prawna społeczeństwa polskiego po komunizmie, „Studia Socjologiczne" 2007, nr 2.

Kurkchiyan M., Comparing Legal Cultures: Three Models of Court for Small Civil Cases, „Journal of Comparative Law" 2010, nr 5 (2).

Marosz M., Resortowe togi, Warszawa 2017.

Matczak M., The Clash of Powers in Poland's Rule of Law Crisis. Tools of Attack and Self-Defense, „Hague J Rule Law” 2020, nr 12 (3).

Miller S., Social Institutions, [hasło w:] The Stanford Encyclopedia of Philosophy, red. E.N. Zalta, https://plato.stanford.edu/archives/sum2019/entries/social-institutions/.

Morawski L., A Critical Response, 3.07.2017, https://verfassungsblog.de/a-critical-response/.

Muszyński K., Skuczyński P., Rozwój i kryzys konstytucji społecznej. Przypadek samorządów zawodowych, Warszawa 2020.

Polacy o zmianach $w$ sadownictwie, komunikat z badań 22/2020, Centrum Badania Opinii Społecznej, Warszawa 2020.

Radziewicz P., Kryzys konstytucyjny i paradygmatyczna zmiana konstytucji, „Państwo i Prawo” 2020, nr 10.

Sadurski W., Polski kryzys konstytucyjny, przeł. Anna Wójcik, Łódź 2020.

Sawczuk T., Nowy liberalizm. Jak zrozumieć i wykorzystać kryzys III RP, Warszawa 2018.

Sciulli D., Theory of Societal Constitutionalism. Foundations of a Non-Marxist Critical Theory, Cambridge 1991.

Skąpska G., Od „legalnej rewolucji” do kontrrewolucji. Kryzys konstytucjonalizmu liberalno-demokratycznego w Polsce, „Przegląd Prawa i Administracji” 2017, nr 110.

Skąpska G., Znieważający konstytucjonalizm i konstytucjonalizm znieważony. Refleksja socjologiczna na temat kryzysu liberalno-demokratycznego konstytucjonalizmu w Europie pokomunistycznej, „Filozofia Publiczna i Edukacja Demokratyczna” 2018, nr 7 (1).

Sokołowski J., Dlaczego Polacy nie broniq sędziów? Szukając wyjścia z błędnego koła (cz. 1), 21.01.2020, https://klubjagiellonski.pl/2020/01/21/dlaczego-polacy-nie-bronia-sedziow-szukajac-wyjscia-z-blednego-kola/.

Społeczne oceny wymiaru sprawiedliwości, komunikat z badań 31/2017, Centrum Badania Opinii Społecznej, Warszawa 2017.

Stambulski M., Populizm a konstytucjonalizm, [w:] Nowy konstytucjonalizm. Polityczność, tożsamość, sfera publiczna, red. A. Czarnota, M. Paździora, M. Stambulski, Warszawa 2021.

Sulikowski A., Apolityczność w prawoznawstwie. Kryzys idei a zjawisko populizmu, „Archiwum Filozofii Prawa i Filozofii Społecznej” 2018, nr 3.

Turner J., The Institutional Order, New York 1997.

Uzelac A., Survival of the Third Legal Tradition?, „Supreme Court Law Review (2 $\left.{ }^{\text {nd }}\right)$ ”2010, nr 49.

Studia nad Autorytaryzmem i Totalitaryzmem 43, nr 1, 2021

(C) for this edition by CNS 
Wigura K., Kuisz J. (red.), The End of the Liberal Mind. Poland's New Politics, Warszawa 2010.

Winczorek J., Muszyński K., Dostęp do prawa wśród matych i średnich przedsiębiorców. Raport z badania empirycznego, Warszawa 2019.

Winczorek J., Muszyński K., Skąd kryzys państwa prawa? Ludzie nie czuli, że formalne instytucje prawne działaja. Trzeba to naprawić, 3.10.2019, https://oko.press/skad-kryzys-panstwa-prawa-ludzie-nie-czuli-ze-formalne-instytucje-prawne-dzialaja-ale-wiadomo-jak-to-naprawic/. 